\title{
Efeito do armazenamento de estacas no enraizamento de roseiras para corte nas quatro estações do ano ${ }^{1}$
}

\author{
DENISE RENATA PEDRINHO; KATHIA FERNANDES LOPES PIVETTA²; PATRÍCIA UNGER CÉSAR PIZETTA²; \\ LAVÍNIA PEREIRA CASALLI² e ISABELE SARZI²
}

\begin{abstract}
RESUMO
Visando a estabelecer melhor programação de plantio e comércio de estacas, este trabalho teve o objetivo de estudar o efeito do período de armazenamento de estacas em câmara fria, no enraizamento de roseiras para corte, nas quatro estações do ano. Utilizaram-se estacas de 'Vega' e 'Versilia Pink', armazenadas por períodos variáveis $(0,3,6$ e 9 dias $)$, em câmara fria $\left(7^{\circ} \mathrm{C} \pm 1^{\circ} \mathrm{C}\right)$, nas quatro estações do ano. Desenvolveu-se o experimento na UNESP, Campus de Jaboticabal (SP). O delineamento experimental utilizado foi o inteiramente casualizado, com quatro repetições e três estacas apicais/parcela. As estacas foram obtidas de roseiras em cultivo no município de Holambra (SP). Após o armazenamento, as estacas foram tratadas com ácido indolbutírico, em pó, na concentração de 2.000 $\mathrm{mg} / \mathrm{L}$ e estaqueadas sob nebulização intermitente. Efetuaram-se as avaliações 30 dias após a estaquia, anotando-se a porcentagem de enraizamento, o número e o comprimento médio de raízes. Concluiu-se que, para 'Vega', o período em que as estacas podem ser armazenadas sem prejuízos para essas características varia de acordo com a estação do ano; para 'Versilia Pink', elas podem ser armazenadas por nove dias, em câmara fria, sem prejuízo na porcentagem de enraizamento, em qualquer estação. Para ambos os cultivares, o enraizamento foi inferior no inverno, e o armazenamento não interferiu no número de raízes, mas sim no comprimento médio de raízes.
\end{abstract}

Palavras-chave: Rosa sp., enraizamento de estacas.

\section{ABSTRACT \\ Effect of cutting storage on rooting of rose cultivars for cut flowers in the four seasons}

The objective of the present study was to evaluate the effect of storage period of cuttings in cold chamber on the rooting of rose during the four seasons, in order to set up a better planting and marketing schedules of cuttings. "Vega" and Versilia Pink cuttings were stored in cold chamber $\left(7^{\circ} \pm 1^{\circ} \mathrm{C}\right)$ for variable periods $(0,3,6$ and 9 days) during the four seasons of the year. It was used a completely randomized experimental design, with four replications of three apical cuttings/per plot. After storage the cuttings were kept under intermittent nebulizing and treated with powder indole-butyric acid at a concentration of $2,000 \mathrm{mg} / \mathrm{L}$. The percentage of rooting, the average number of roots and root length were evaluated and recorded on the $30^{\text {th }}$ day after staking. It was concluded that "Vega" cuttings could be stored without damage to those characteristics for variable periods that depended on the season. On the other hand, "Versilia Pink" cutting could be stored during nine days in cold chamber without damage to rooting percentage independent of the season. Cold storage did not interfere on root number but affected average root length for both cultivars.

Keywords: Rosa sp., cutting rooting.

\footnotetext{
${ }^{1}$ Artigo com base na dissertação apresentada pela primeira autora à FCAV/UNESP, Câmpus de Jaboticabal, para a obtenção do título de Mestre em Agronomia.

${ }^{2}$ Departamento de Produção Vegetal - FCAV/UNESP, Via de Acesso Prof. Paulo Donato Castelane, km 5, 14884-900 Jaboticabal (SP).
} 


\section{INTRODUÇÃO}

A roseira, uma das principais floríferas cultivadas em todo o mundo, é propagada comercialmente por enxertia ou por estaquia.

$\mathrm{Na}$ estaquia herbácea, processo bastante utilizado, as estacas são retiradas de hastes floríferas comerciais (PIVETTA, 1999) e, normalmente, cortadas e estaqueadas logo em seguida ao corte das hastes.

O armazenamento das estacas é importante, na medida em que permite melhor programação de plantio e, também, o estabelecimento do seu comércio, possibilitando maior controle da sanidade das estacas ou mudas, tendo em vista que o produtor não precisará preocupar-se com a produção de mudas, mas somente com o cultivo, comprando mudas sadias de empresas idôneas.

Essa prática já é comum para outras culturas. BEHRENS (1988), POL (1988), SALINGER (1991), ARBÓS LAVILA (1992), CUQUEL et al (1992) e ALMEIDA (2001) fizeram considerações sobre o armazenamento de estacas de crisântemo, enraizadas ou não. Outras poucas informações foram encontradas sobre armazenamento de estacas lenhosas de Cordyline rubra (ANDRADE et al., 1999) e para o porta-enxerto Rosa indica x multiflora (HAYASHI \& GRAZIANO, 1999). Não se encontrou na literatura nenhuma referência ao armazenamento de estacas semi-herbáceas de roseira.

O presente trabalho teve o objetivo de estudar o efeito do período de armazenamento no enraizamento de estacas de roseiras de corte, em câmara fria, nas quatro estações do ano.

\section{MATERIAL E MÉTODOS}

$\mathrm{O}$ experimento foi instalado na Faculdade de Ciências Agrárias e Veterinárias (FCAV/UNESP), município de Jaboticabal (SP), a $21^{\circ} 15^{\prime}$ latitude sul e $48^{\circ} 18^{\prime}$ 'longitude oeste, a 595 metros acima do nível do mar.

A classificação climática, segundo Köppen, é do tipo Cwa, ou seja, subtropical úmido com estiagem no inverno (CAMARGO et al., 1974; RUSSO JÚNIOR, 1980).

Utilizou-se o delineamento experimental inteiramente casualizado, sendo os tratamentos quatro períodos de armazenamento (0, 3, 6 e 9 dias), em câmara fria $\left(7^{\circ} \mathrm{C}\right.$ com uma variação de $\left.1^{\circ} \mathrm{C}\right)$ e quatro estações do ano (inverno: 7/2001; primavera: 11/ 2001; verão: $2 / 2002$ e outono: $5 / 2002$ ), em quatro repetições, com dez estacas/parcela.

As hastes dos cultivares Vega e Versilia Pink foram coletadas de uma área de cultivo no município de Holambra (SP), localizado a $22^{\circ} 38^{\prime}$ latitude sul e a $47^{\circ} 03^{\prime}$ de longitude oeste, a 600 metros acima do nível do mar.

Em seguida ao corte, colocaram-se as hastes em baldes contendo água filtrada, em altura aproximada de $15 \mathrm{~cm}$, sem que houvesse folhas em contato com a água; em seguida, transportaram-nas para Jaboticabal, em veículo com ar condicionado.

Utilizaram-se estacas apicais, retiradas a partir da primeira folha com cinco folíolos, as quais se acondicionaram em sacos de plástico e colocaram em câmara fria $\left(7^{\circ} \mathrm{C}\right.$ com uma variação de $\left.1{ }^{\circ} \mathrm{C}\right)$.

Após o período de armazenamento, trataram-se as estacas com ácido indolbutírico, em pó, na concentração de $2.000 \mathrm{mg} / \mathrm{L}$, estaqueando-se em tubetes contendo vermiculita de textura média. Em seguida, colocaram-nas para enraizar sob nebulização intermitente, no Viveiro Experimental de Plantas Ornamentais e Florestais da FCAV/UNESP, Câmpus de Jaboticabal.

Realizaram-se as avaliações 30 dias após a estaquia,quando se anotaram a porcentagem de enraizamento, o número e o comprimento médio de raízes.

Analisaram-se os dados coletados estatisticamente em esquema fatorial 4 x 4 (estações x períodos). Realizou-se a análise da variância e, posteriormente, quando necessário, na comparação das médias dos tratamentos, utilizou-se o teste de Tukey a 5\% de probabilidade ou a regressão polinomial a fim de se verificar o comportamento dos tratamentos ao longo do período de armazenamento (BANZATTO \& KRONKA, 1992).

\section{RESULTADOS E DISCUSSÃO}

Observa-se, nas Tabelas 1 e 2, que o inverno apresentou as menores médias em todas as características estudadas, para ambos os cultivares. Resultados semelhantes foram observados em outros estudos sobre o enraizamento de estacas de outras roseiras.

Analisando-se a porcentagem de enraizamento do cultivar Vega (Tabela 1), verifica-se que houve diferença significativa na interação das estações do 
ano e do período de armazenamento, ou seja, o período em que as estacas podem ser armazenadas em câmara fria, sem prejudicar a porcentagem de enraizamento, é variável nas diferentes estações do ano.

No inverno (Tabela 1), houve ajuste de regressão cúbica. Nota-se, na Figura $1 \mathrm{~A}$, que a porcentagem de enraizamento foi diminuindo com o passar dos dias até seis dias de armazenamento, e do sexto ao nono dia, ela aumentou. Na primavera (Tabela 1), não houve ajuste de regressão, ou seja, tanto as esta- cas não armazenadas, quanto as armazenadas até os nove dias, tiveram alta porcentagem de enraizamento em todos os períodos amostrados. No verão, a porcentagem de enraizamento aumentou com o passar dos dias (Figura 1A) e, no outono, foi de 100\% para todos os períodos amostrados.

O armazenamento de estacas de crisântemo em câmara fria tem mostrado que, além de não prejudicar o enraizamento, pode até ser uma prática benéfica para o experimento (SALINGER, 1991; POL, 1988).

Tabela 1. Análise da variância (quadrados médios) e médias para porcentagem de enraizamento, número de raízes e comprimento médio de raízes $(\mathrm{cm})$ de estacas de roseira 'Vega' armazenadas em câmara fria, nas quatro estações, em diferentes períodos $(0,3,6,9$ dias $)$

\begin{tabular}{|c|c|c|c|c|}
\hline Causas de Variação & GL & Enraizamento $^{1}$ & Número de raiz ${ }^{2}$ & Comprimento de raiz \\
\hline & & $\%$ & & $\mathrm{~cm}$ \\
\hline Estações (E) & 3 & $5883,26 * *$ & $12,44 * *$ & $39,95 * *$ \\
\hline Período (P) & 3 & $773,38 *$ & $0,07 \mathrm{NS}$ & $3,55 \mathrm{NS}$ \\
\hline E X P & 9 & $987,94 *$ & $1,61 \mathrm{NS}$ & $5,36 * *$ \\
\hline Resíduo & 48 & 216,59 & 0,84 & 1,89 \\
\hline $\mathrm{CV} \%$ & & 19,13 & 24,91 & 35,53 \\
\hline Média & & 76,94 & 3,67 & 3,88 \\
\hline \multicolumn{5}{|l|}{$\begin{array}{l}\text { Regressão Polinomial } \\
\text { Inverno }\end{array}$} \\
\hline Regressão Linear & 1 & $3381,59 * *$ & - & $2,96 \mathrm{NS}$ \\
\hline Regressão Quadrática & 1 & $4556,25 * *$ & - & $2,67 \mathrm{NS}$ \\
\hline Regressão Cúbica & 1 & $1199,34 *$ & - & $0,98 \mathrm{NS}$ \\
\hline \multicolumn{5}{|l|}{ Primavera } \\
\hline Regressão Linear’ & 1 & $15,36 \mathrm{NS}$ & - & $0,40 \mathrm{NS}$ \\
\hline Regressão Quadrática & 1 & $76,83 \mathrm{NS}$ & - & $0,85 \mathrm{NS}$ \\
\hline Regressão Cúbica & 1 & $138,29 \mathrm{NS}$ & - & $0,01 \mathrm{NS}$ \\
\hline \multicolumn{5}{|l|}{ Verão } \\
\hline Regressão Linear & 1 & $983,45 *$ & - & $18,34 * *$ \\
\hline Regressão Quadrática & 1 & $307,33 \mathrm{NS}$ & - & $8,26 *$ \\
\hline Regressão Cúbica & 1 & $553,19 \mathrm{NS}$ & - & $0,11 \mathrm{NS}$ \\
\hline \multicolumn{5}{|l|}{ Outono } \\
\hline Regressão Linear & 1 & - & - & $7,51 \mathrm{NS}$ \\
\hline Regressão Quadrática & 1 & - & - & $7,59 \mathrm{NS}$ \\
\hline Regressão Cúbica & 1 & - & - & $9,22 *$ \\
\hline \multicolumn{5}{|l|}{ Médias } \\
\hline Inverno & & $48,73 \mathrm{~b}$ & $2,53 \mathrm{c}$ & $1,59 \mathrm{~b}$ \\
\hline Primavera & & $87,81 \mathrm{a}$ & $4,62 \mathrm{a}$ & $5,20 \mathrm{a}$ \\
\hline Verão & & $81,23 \mathrm{a}$ & $3,53 \mathrm{~b}$ & $4,23 \mathrm{a}$ \\
\hline Outono & & $90,00 \mathrm{a}$ & $4,02 \mathrm{ab}$ & $4,49 \mathrm{a}$ \\
\hline
\end{tabular}

Médias transformadas em: ${ }^{1}$ arco seno $\sqrt{\mathrm{x} / 100 ;} \quad 2 \sqrt{\mathrm{x}}+0,5 ; \quad \mathrm{NS}(\mathrm{P}>0,05) *(\mathrm{P}<0,05)(\mathrm{P}<0,01)$ 

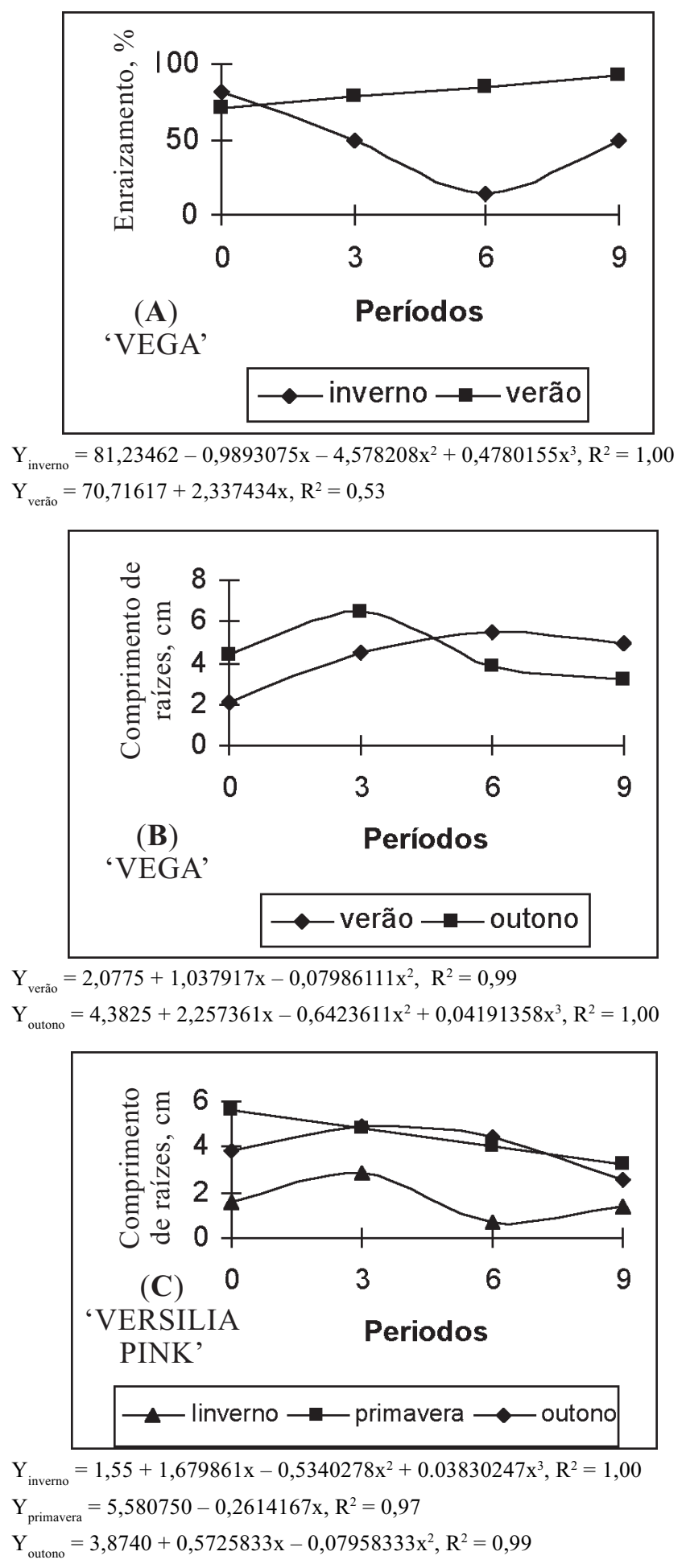

Figura 1. Curvas de regressão entre os dias de armazenamento de estacas e (A) porcentagem de enraizamento (valores transformados em arco seno $\sqrt{\mathrm{x}} / 100)$ no verão e no inverno e (B) comprimento médio de raízes no verão e no outono, para a roseira 'Vega' e entre (C) comprimento médio de raízes no inverno, na primavera e no outono, para a roseira 'Versilia Pink'
Em relação às características que definem a qualidade do sistema radicular, ou seja, número e comprimento médio de raízes, observa-se (Tabela 1), para o cultivar Vega, que, em relação ao número de raízes, não houve efeito significativo para a interação nem diferença entre os períodos amostrados, indicando que, em todas as estações, o número de raízes das estacas não armazenadas em câmara fria foi semelhante ao daquelas armazenadas. No inverno, porém, o número de raízes foi estatisticamente inferior quando comparado ao das demais estações.

Quanto ao comprimento de raiz, no entanto, a interação das estações do ano e dos períodos de armazenamento foi significativa. No inverno e na primavera, não houve ajuste de regressão alguma, ou seja, o armazenamento não interferiu nos resultados. No verão, houve ajuste de regressão quadrática (Figura 1B), ou seja, o comprimento das raízes aumentou progressivamente até seis dias de armazenamento, diminuindo a seguir, e, no outono, o comprimento das raízes aumentou até três dias de armazenamento, diminuindo a seguir.

Na Tabela 2, nota-se, para o cultivar Versilia Pink, quanto à porcentagem de enraizamento e número de raízes, que a interação entre estações do ano e períodos de armazenamento não foi significativa, e também não houve diferença significativa para os períodos amostrados, ou seja, em todas as estações, as estacas podem ser armazenadas por nove dias, sem prejuízo na porcentagem de enraizamento e no número de raízes.

Houve diferença significativa nas estações, observando-se que, no inverno, a porcentagem de enraizamento foi significativamente inferior à das demais estações e, também, semelhantemente ao que ocorreu com o cultivar Vega, no inverno, as estacas tiveram de modo significativo menos raízes do que quando comparadas às das demais estações.

Quanto à característica comprimento médio de raízes, verifica-se que houve diferença significativa na interação das estações e dos períodos de armazenamento.

No inverno, houve ajuste de regressão cúbica, em que se observa (Figura 1C) que o comprimento das raízes aumentou até o terceiro dia de armazenamento. Na primavera, houve ajuste de regressão linear negativa, verificando-se que o comprimento diminuiu com o passar dos dias, e, no outono, houve ajuste de regressão quadrática, a qual mostra que o comprimento aumentou até o terceiro dia de armazenamento, diminuindo a seguir. 
No verão, não houve ajuste de regressão alguma, ou seja, o armazenamento não interferiu nas características avaliadas (Tabela 2).

Esses cultivares de corte apresentaram resultados semelhantes ao relatado para o porta-enxerto Rosa indica x multiflora (HAYASHI \& GRAZIANO, 1999), sendo o armazenamento das estacas a frio considerado um procedimento que pode ser recomendado, exceto no inverno, para 'Vega'.
O armazenamento de estacas de crisântemo em câmara fria tem mostrado que, além de não prejudicar o enraizamento, pode até ser uma prática benéfica (SALINGER, 1991; POL, 1988).

Neste estudo, observa-se efeito positivo do armazenamento em câmara fria, com aumento da porcentagem de enraizamento para 'Vega', no verão, aumento do comprimento médio das raízes, para 'Vega', no verão e no outono, e para 'Versilia Pink', no inverno e no outono.

Tabela 2. Análise da variância (quadrados médios) e médias para porcentagem de enraizamento, número de raízes e comprimento médio de raízes $(\mathrm{cm})$ de estacas de roseira"'Versilia Pink' armazenadas em câmara fria, nas quatro estações, em diferentes períodos $(0,3,6,9$ dias $)$

\begin{tabular}{|c|c|c|c|c|}
\hline Causas de Variação & GL & Enraizamento $^{1}$ & Número de raiz² & Comprimento de raiz \\
\hline & & $\%$ & & $\mathrm{~cm}$ \\
\hline Estações (E) & 3 & $6873,64 * *$ & $16,49 * *$ & $24,48^{* *}$ \\
\hline Período (P) & 3 & $158,40 \mathrm{NS}$ & $0,12 \mathrm{NS}$ & $4,31^{*}$ \\
\hline E X P & 9 & $338,82 \mathrm{NS}$ & $0,82 \mathrm{NS}$ & $2,56^{*}$ \\
\hline Resíduo & 48 & 506,71 & 0,46 & 1,21 \\
\hline CV\% & & 30,17 & 24,28 & 32,56 \\
\hline Média & & 74,60 & 2,79 & 3,38 \\
\hline \multicolumn{5}{|l|}{ Regressão Polinomial } \\
\hline Inverno & & - & - & \\
\hline Regressão Linear & 1 & - & - & $1,55 \mathrm{NS}$ \\
\hline Regressão Quadrática & 1 & - & - & $0,37 \mathrm{NS}$ \\
\hline Regressão Cúbica & 1 & - & - & $7,70^{*}$ \\
\hline \multicolumn{5}{|l|}{ Primavera } \\
\hline Regressão Linear & 1 & - & - & $12,30 * *$ \\
\hline Regressão Quadrática & 1 & - & - & $0,16 \mathrm{NS}$ \\
\hline Regressão Cúbica & 1 & - & - & $0,21 \mathrm{NS}$ \\
\hline \multicolumn{5}{|l|}{ Verão } \\
\hline Regressão Linear & 1 & - & - & $1,78 \mathrm{NS}$ \\
\hline Regressão Quadrática & 1 & - & - & $0,22 \mathrm{NS}$ \\
\hline Regressão Cúbica & 1 & - & - & $0,03 \mathrm{NS}$ \\
\hline \multicolumn{5}{|l|}{ Outono } \\
\hline Regressão Linear & 1 & - & - & $3,71 \mathrm{NS}$ \\
\hline Regressão Quadrática & 1 & - & - & $8,21^{*}$ \\
\hline Regressão Cúbica & 1 & - & - & $0,08 \mathrm{NS}$ \\
\hline \multicolumn{5}{|l|}{ Médias } \\
\hline Inverno & & $45,00 \mathrm{~b}$ & $1,33 \mathrm{c}$ & $1,59 \mathrm{~b}$ \\
\hline Primavera & & $87,81 \mathrm{a}$ & $3,58 \mathrm{a}$ & $4,40 \mathrm{a}$ \\
\hline Verão & & $90,00 \mathrm{a}$ & $3,35 \mathrm{ab}$ & $3,57 \mathrm{a}$ \\
\hline Outono & & $75,61 \mathrm{a}$ & $2,92 \mathrm{~b}$ & $3,94 \mathrm{a}$ \\
\hline
\end{tabular}

Médias transformadas em: ${ }^{1}$ arco seno $\sqrt{\mathrm{x}} / 100 ; \quad 2 \sqrt{\mathrm{X}}+0,5 ; \quad \mathrm{NS}(\mathrm{P}>0,05) *(\mathrm{P}<0,05)(\mathrm{P}<0,01)$ 
Para ambos os cultivares, o enraizamento foi inferior em quantidade e qualidade no inverno.

\section{CONCLUSÕES}

1. Para ambos os cultivares, o enraizamento foi inferior no inverno em todas as situações estudadas.

2. Para 'Vega', o período em que as estacas puderam ser armazenadas em câmara fria, sem prejudicar a porcentagem de enraizamento, foi variável conforme a estação do ano.

3. Para 'Versilia Pink', as estacas puderam ser armazenadas por nove dias, em câmara fria, sem prejuízo na porcentagem de enraizamento, em qualquer estação.

Para ambos os cultivares, o armazenamento de estacas não interferiu no número de raízes, mas, sim no seu comprimento.

\section{REFERÊNCIAS BIBLIOGRÁFICAS}

ALMEIDA, J.B.S.A.de Enraizamento de estacas de cultivares de crisântemo de corte (Dendranthema grandiflora Tzvelev): efeito do armazenamento de estacas em diferentes épocas do ano e rizogênese. Jaboticabal: Faculdade de Ciências Agrárias e Veterinárias, UNESP, 2001. 66p. Dissertação (Mestrado em Agronomia) -

ANDRADE, T.O. de et al. Efeitos de tratamentos de préarmazenamento e da temperatura de armazenamento na brotação de estacas de Cordyline rubra 'Bruanti'. In: CONGRESSO BRASILEIRO DE FLORICULTURA E PLANTAS ORNAMENTAIS, 12, Jaboticabal, 1999. Resumos... Jaboticabal: SBFPO/FCAV/UNESP, 1999. p.55.

ARBÓS LAVILA, A.M. El crisântemo: cultivo, multiplicación y enfermidades. Madrid: Mundi-Prensa, 1992. 170p.
BANZATTO, D.A. \& KRONKA, S.N. Experimentação agrícola. 2 ed. Jaboticabal: FUNEP, 1992. 247p.

BEHRENS, V. Storage of unrooted cuttings. In: DAVIS, T.D., HAISSIG, B.E. \& SANKHLA, N. Adventitious root formation in cuttings. Portland: Dioscorides, 1988. v.2, p. $235-247$.

CAMARGO, A.P. et al. Clima do Estado de São Paulo. In: Zoneamento agrícola do Estado de São Paulo. São Paulo: Secretaria de Agricultura, 1974. v.1,p. 51-86.

CUQUEL, F.L.; GRANJA, N.do P. \& MINAMI, K. Avaliação do enraizamento de estacas de crisantemo (Chrysanthemum morifolium L.) cv. White Reagan 606 tratadas com ácido indolbutírico (IBA). Scientia Agricola, Piracicaba, v.49, n.1, p.15-22, 1992.

HAYASHI, A.H. \& GRAZIANO, T.T. Enraizamento de estacas do porta-enxerto Rosa indica x multiflora In: CONGRESSO BRASILEIRO DE FLORICULTURA E PLANTAS ORNAMENTAIS, 12, Jaboticabal, 1999, Resumos... Jaboticabal: SBFPO/FCAV/UNESP, 1999. p.50.

PIVETTA, K.F.L. Propagação de roseiras. In: WORKSHOP SOBRE AVANÇOS NA PROPAGAÇÀO DE PLANTAS LENHOSAS, 2, Lavras, 1999. Palestras... Lavras:UFLA, 1999. p.41-49.

POL, P.A. Partial replacement of the rooting procedure of Chrysanthemum morifolium cuttings by pre-rooting storage in the dark. Acta Horticulturae, Wageningen, v.226, p.519-524, 1988.

RUSSO JÚNIOR, M. Dados climáticos auxiliares para planejamento e projeto de sistemas de irrigação. São Paulo: CESP, 1980. 13p.

SALINGER, J.P. Crisântemos. In: Produción comercial de flores. Zaragoza: Acribia, 1991. cap. 16, p.223-244. 